
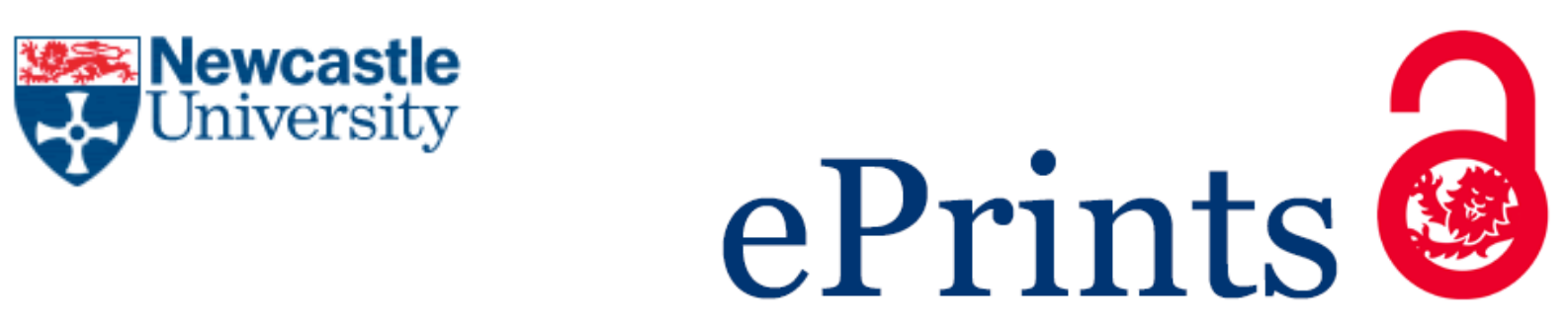

Pain R.

Social geography: participatory research. Progress in Human Geography 2004, 28(5), 652-663.

\title{
Copyright:
}

(C) 2004 (Arnold). Reprinted by permission of SAGE Publications.

DOI link to article:

https://doi.org/10.1191/0309132504ph511pr

Date deposited:

$21 / 12 / 2017$

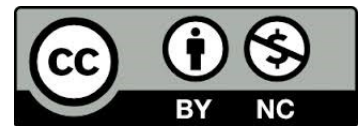

This work is licensed under a Creative Commons Attribution-NonCommercial 3.0 Unported License 


\section{Social geography: participatory research}

\section{Rachel Pain}

This second of three reviews of action-oriented research in social geography focuses on one area of this work which is thriving. Moving, like many good ideas, from the field conventionally viewed as 'development' to wider application, participatory research (PR) has seen rapid expansion in recent years (see Breitbart 2003; Kesby et al 2004; Pratt 2000). It has particular attractions for social geographers, who are beginning to contribute to wider debates and critiques around its philosophies, theories and practices. They face, too, all of the problems involved in getting academic geography 'onto the streets' (Fuller and Kitchin 2004).

\section{Why social geography, why now?}

\section{A space for action}

In creating new spaces for engagement beyond the academy 'where researchers and participants can reshape our understandings' (McIntyre 2000,3), PR is one answer to recent calls for more relevant, morally aware and non-hierarchical practice of social geography which engages with inequality to a greater degree (Cloke 2002; Gregson 2003; Kitchin and Hubbard 1999; Pain 2003a; Proctor and Smith 1999). Fuller and Kitchin (2004) place it as the most recent and promising chapter in radical geography's 35-year history. The keystone of PR is that it involves those conventionally 'researched' in some or all stages of research, from problem definition through to dissemination and action. Ownership of the research is shared with participants, who negotiate processes with the academic researcher ${ }^{1}$. Education and knowledge building are also often viewed as important outcomes. PR involves, then, a collaborative and non-hierarchical approach which overturns the usual ways in which academics work outside universities. Moser and McIlwaine (1999) outline three further benefits - conceptually, particular tools are effective for exploring interrelationships (in their research, between violence and poverty); operationally, PR can contribute to community projects and help to join up those with differing aims (e.g. mainstreaming the issue of violence on other programs); and in terms of capacity-building, it often involves training local researchers, NGOs or activists.

No single discipline is responsible for the development of PR (Herlihy and Knapp 2003). The current interest has evolved from 'participatory rural appraisal' techniques used in community development work in the south (Chambers 1997), but PR dates back to the 1970s (Whyte 1991; Freire 1971) and has roots in earlier action research frameworks (e.g. Lewin 1946). Feminist critiques of conventional research and early forms of PR have had a major influence since the 1980s, with feminist principles including reciprocity and critical questioning of who benefits from research outcomes, and feminist scholars, prominent in PR (e.g. Kindon 2003; Maguire 1987; McIntyre 2000). Social geographers' work draws on several approaches, reflecting their sensitivity to context, including 'participatory rural appraisal' (Kindon 1995, 1998; Rocheleau and Thomas-Slayter 1995), 'participatory urban appraisal' in cities where communities are diverse and difficult to define (Moser and McIlwaine 1999), 'participatory mapping' which is becoming a keystone in development and research activity in Latin America (Herlihy and Knapp 2003), 'participatory action research', more common in high income countries (Cahill et al forthcoming; Cameron and 
Gibson forthcoming; McIntyre 2000; Pratt 1999), and 'participatory appraisal' used with marginalized communities in Britain (Fuller, Mellor et al 2003; Fuller, O’Brien et al 2003). Given this diversity, the depth of participation defines PR for many (see Herlihy and Knapp 2003; Kesby et al 2004; Pain and Francis 2003). This review includes examples from both developing and developed countries, but emphasises the latter, where participatory approaches and surrounding debates have a shorter history.

\section{The spatialities of participatory research}

PR is well suited to the subject matter and approaches of social geography. Firstly, specific participatory techniques such as mapping and timelines are useful in highlighting the spatial and temporal dimensions of issues (Herlihy and Knapp 2003; Kesby 2000). Secondly and more broadly, participatory approaches lend themselves to research where people's relations with and accounts of space, place and environment are of central interest. Investigation of how certain cultural identities are tied to place is a common concern (McIntyre 2003; Kindon 2003; Offen 2003). PR is designed to be context specific, forefronting local conditions and local knowledge, and producing situated, rich and layered accounts. It often results in thick descriptions of place, as 'in representing the voices of a neighbourhood, one also represents the neighbourhood itself' (Mattingly 2001, 452), although Sanderson and Kindon warn that 'participatory processes produce knowledge specific to their process and participants rather than 'uncover' 'local knowledge' (2004, 125; their emphasis). Thirdly, PR encourages and enables the drawing of multiple connections between issues and processes at different scales. Cahill (submitted) describes how young women moved from their concern with the particular local problems they faced in their neighbourhood to awareness of their wider global context and causes such as gentrification. Nonetheless, as Mohan (1999) suggests, there is a contradiction between the global causes of social and economic marginalization, and PR's focus on local and personal knowledge or a sometimes utopian notion of development where the state disappears.

\section{A strategy for countering exclusion}

One of the main benefits of PR perceived by social geographers is its ability to forefront the perspectives of marginalized groups and actively challenge social exclusion with them (Cahill submitted; Chambers 1997). PR is a method for bringing new voices into the academy, not just incorporating a singular voice of 'difference' but interrogating different perspectives and the spaces between them (Cahill submitted). Those currently receiving most attention in participatory social geography research are children and young people. This was prompted by wider imperatives about children's participation and the fact that the power relations involved in age are so unequal (Matthews and Limb 1999, Hart 1997), and also because the bulk of work in children's geographies has had no impacts for children (Smith 2004). A number of researchers have used PR to uncover children's experiences of rurality. Leyshon (2002) spent 14 months undertaking research in villages in south west England, holding multiple roles as researcher, youth worker and representative of a voluntary youth organisation which sometimes conflicted. Nairn et al (2003) set up Youth Advisory Groups to advise on the design and dissemination of their research. Juckes Maxey (2004) reports on participatory research undertaken to consider the nature of young people's participation in adult-organised groupings. Others have focused on marginalised groups of young people in urban areas. Young (2003) examines the effects of residential restructuring on young people's identities on a Scottish estate, 
while Cope and Halfhill (2003) are exploring the conceptualisations of urban space of children of colour in low income areas of Buffalo. In inner city New York neighbourhoods, McIntyre (2000) focuses on how 11-13 year olds negotiate exclusion and violence in daily life, and Cahill et al (forthcoming) explore economic change and young women's social identities. Leavitt et al (1998) conducted related research in a poorer Los Angeles neighbourhood. In Herman and Mattingly's (1999) work, also in inner city areas in California, young people explore connections to notions of community and participation in public space. In north east England, Fuller, O'Brien et al (2003) have worked with graffiti artists on their views of legal sites, while research on experiences of crime victimization and fear has engaged with young offenders, homeless young people, those excluded from school and those labelled at risk of social exclusion (Gaskell 2002; Pain 2003b; Pain and Francis 2004).

Owing to the impact of postcolonial perspectives on research methodology and ethics (McEwan 2003; Peake 2000), PR is also widely used with ethnic minority groups and indigenous populations. Here research often concerns identifying local knowledges and rights, and is harnessed by communities for change on their terms (Kindon 2003; Herlihy and Knapp 2003; Smith 2003). One issue which has been more visible here than in work with (perhaps less empowered) young participants has been clashes between the ethical and moral standpoints of academic researchers and participants. Randstrom and Deur (1999) argue that we need to go beyond Eurocentric conceptions of ethics, as concepts such as 'confidentiality' and 'benefit' are understood very differently between individuals and across cultures (see also Kindon and Latham 2002; Kitchin 1999; Sanderson and Kindon 2004).

Elsewhere in feminist geography, PR has proven effective in highlighting women's labour, needs and rights within a broader context of gender relations (see the landmark work of Townsend et al 1995), for example McIntyre's (2003) study of the lives and communities of working class women in Belfast, Pratt's (1999) collaborative research with migrant communities of women in Canada, and Chouinard (2004) on women's struggles for employment rights in Canada, France and Guyana. In one of the first applications of PR to gender and development, Kindon's (1995, 1998) work with rural, illiterate Balinese women revealed strategic gender needs which were masked by gender myths about equality. The research of Opondo (2003) and colleagues has established highly gendered patterns of labour in Kenya's tobacco farming economy, and raised issues with workers in the cut flower industry ranging from employment insecurity and sexual harassment to inadequate maternity leave (Dolan et al 2003). Peake (2000) has conducted extensive research in collaboration with the women's development organisation Red Thread into experience and perceptions of domestic violence and reproductive health in Guyana. Kesby's (2000, 2003) research has engaged with women on issues around HIV in Zimbabwe, while in Canada Freeman (2004) is developing 'illness journeys' with women diagnosed with endometriosis (see www.endostudy.com).

A small number of geographers have worked participatively with people with disabilities (see Chouinard 2000; Kitchin 2001). McFarlane (2004) has developed techniques to enable participation of visually impaired women and women with various physical impairments in her work on the socio-spatial barriers to motherhood, while Chouinard (2004) is directing a virtual and community-based disability research and training network. Others have focused on issues for poor urban communities 
including financial exclusion in north east England (Fuller, Mellor et al 2003) and the impact of violence on social exclusion in Colombia and Guatamala (McIlwaine and Moser 2000, 2001). Cieri (2003a) has conducted innovative research with lesbian women, comparing their mental maps of social space with official representations of gay Philadelphia.

\section{Revitalizing methodology}

As well as having strategic benefits, PR is one of the most exciting new areas for methodological development. It has introduced a new toolkit, participatory diagramming, which is adaptable to any setting, effective at drawing in people normally excluded from research, and able to overcome some barriers to participation of culture, literacy or disability. Diagramming has been used in social geography within and outside a broader participatory approach (Fuller, Mellor et al 2003; Fuller, O'Brien et al 2003; Kesby 2000; Pain and Francis 2004; Young and Barratt 2001; for a critique see Pain and Francis 2003). Participatory mapping is one variant also growing in popularity (see Herlihy and Knapp 2003), demonstrated in Cravey et al's (2000) research with farmers on health concerns over agricultural chemicals, and Hartfield's work with multicultural communities reassessing sites of built heritage (Hartfield and Kindon 2003).

A small group of critical geographers have employed arts techniques in PR, a more established practice in community development, demonstrating the 'unique communicative and social power that the arts can exert within the public sphere' (Cieri 2004, 2). Pratt and Kirby (2003) observe how nurses raised political issues through the medium of theatre. Bailey et al's (2004) research on the impact of foot and mouth disease on British farmers' well-being involved an art exhibition as part of a multi-method strategy to create 'citizens' epidemiologies'. In Herman and Mattingly's (1999) research with young people in inner city areas, they collaborated with community arts projects including theatre (see Mattingly 2001), music, dance and photography. This provided 'spaces of self-representation and articulation' for young people's benefit (Herman and Mattingly 1999, 210) and 'spaces of encounter between ourselves and the communities we study' (219).

The rich accounts which emerge from PR tend to be based on qualitative enquiry, but methodological dogmatism is rare, since the central concerns are appropriateness to context, the depth of participation and nature of outcomes. As the dualism between critical research and quantification is further dismantled (Kwan 2002; Peake 2000), there are exciting possibilities for combining participatory research and geographical information systems (GIS) in order to democratise and harness technology for bottom-up social change (Abbott et al 1998; Elwood 2004; Williams and Dunn 2003). For example, the Center for Urban Policy Research at Rutgers University is integrating GIS across a range of areas in its participatory neighbourhood revitalization work (http://policy.rutgers.edu:16080/cupr/rcopc/). Participatory mapping can be an antidote to growing domination of GIS and GPS technologies in mapping resources, needs and rights (Stocks 2003). Participatory 3-D modelling (Rambaldi and Lanh 2003) involves stand-alone relief models which can be linked to GIS, but which provide handleable user-friendly tools for people to collect and analyse data. Cieri is using texts and tools of visualization drawn from geography, the arts and popular culture, and multi-layered cognitive maps (see http://www.acme- 
journal.org/Volume2-2) as means to rewrite the rules of communicating geographical information in her work with lesbian women (2003a) and African Americans (2003b).

Other innovative methods becoming popular in participatory social geography include self-directed photography with young people (Leavitt et al 1998; Leyshon 2002; McIntyre 2000); 'photovoice' used by McIntyre (2003) to combine photography with women's accounts of their lives and communities; participatory video, which for Kindon (2003) provides 'a feminist way of looking'; storytelling, collage and community resource inventories (Kindon 1995, 1998; McIntyre 2000); and personal diaries, film-making, tape-slide presentations, and email (Leyshon 2002). Peer research has been used to give participants further control of fieldwork (Blake 2004; Cahill et al forthcoming; Gill and Pain 2002; Nairn and Smith 2003).

\section{Input into wider debates and critiques around participation}

As PR has been taken up relatively late by social geographers in any numbers, many have reflected on its philosophies and practices and their implications for wider issues around academic praxis These reflections include some vociferous critiques.

\section{Power}

Power and empowerment are central concepts in PR, both in attempts to minimalise the 'us and them' between academic researcher and participants, and in reversing conventional assumptions about who owns and benefits from research (see Kindon 2003). However, the conceptualisation of power has been one of the main issues of contention in a growing critical literature (Cooke and Kothari 2001). As well as sometimes essentialising power in terms of 'haves' and 'have nots', and romanticising primitivist notions of 'the poor' and their relations to 'elites' (Mohan 1999), participatory structures have their own underlying relations of power (Pugh and Potter 2003). For some, these strengthen rather than reverse traditional relations in the research process, for example in re-authorising other knowledges as more organic and primitive (Mohan 1999). A parallel is provided by Sanderson and Kindon (2004) in their account of the cross-cultural production of knowledge in the participatory development process, which is not always inclusive of alternative and indigenous knowledges and sometimes subordinates them rather than increasing their power. They argue that this danger needs to be actively and critically negotiated by practitioners and researchers. In a promising area of development, social geographers are currently drawing out the connections and mutual insights between PR and poststructuralism (Cameron and Gibson forthcoming; Dempsey and Rowe 2004; Kesby 2004). Kesby's recent work has been concerned with the ways that power shifts and reforms within and through PR processes.

The concept of empowerment in PR has been criticised for implying a paternalistic relationship between researcher and researched and ignoring the extent to which people can self-empower (Leyshon 2002). There is a tendency to assume that power can always be transferred, that academic researchers have this intention and that participants are willing to be empowered in this way (Kitchin 1999; Wilton 2004). Given the increasing use of PR in policy research, geographers need to be wary; 'empowerment' can mean empowering people to take part in the modern sector of developing societies (Henkel and Stirrat 2001), and participatory processes may give an impression of change while serving to contain planning or stifling dissent (Pugh and Potter 2003). 
Inequalities within communities are sometimes poorly reflected by $\mathrm{PR}$, as has been illustrated in the subordination of women's voices and interests unless these are explicitly addressed (Guijt and Shah 1998; Lennie 1999; Maguire 1987; Momsen 2003). The power relations which participants are enmeshed in can make it difficult to participate fully, even where they wish to. In researching violence, for example, some are reluctant to speak where it would jeopardise their safety (Moser and McIlwaine 1999). In practice, academics often have most input and retain overall control in research (Pain and Francis 2003). Monk et al (2003) document the differential power relationships at work between participants on a large collaborative project. Their reflection on the position of librarians and clerical staff within the project and within the University hierarchy implies that notions of 'broadening participation' could go much further.

\section{Ethics and reflexivity}

In geographical research, ethical codes have tended to be about having no negative impacts, not about the need to have positive impacts. Viewing ethics alternatively as 'processes that bring about more just social relations' (Herman and Mattingly 1999; Kindon and Latham 2002) not only brings academic and participants' notions of 'ethics' closer (Randstrom and Deur 1999), but necessitates a far more active approach to participation and change. The gold standard of reflexivity, for example, does not directly benefit those who take part in research (Herman and Mattingly 1999). There is no long tradition of reflexivity in PR. The relationship between having an activist stance and self-reflexivity is a troubled one, despite often arising from the same set of politics (Kobayashi 2003). Sometimes participatory research is reported almost as though there is no researcher/writer voice or perspective, only a 'community' view (Pain and Francis 2003). Because of these dangers, critical reflexivity is vital, both to explicate the role of outside researcher and knowledge (Herlihy and Knapp 2003; Wilton 2004) and to examine how far goals of empowerment and change are being met (Cooke and Kothari 2001). Negotiating ethics as part of participatory research processes enables greater reflexivity by all involved (Kindon and Latham 2002).

\section{Representation}

One of the central tenets of PR is that research participants self-represent, rather than being represented by those with authority. PR provides one of the best opportunities for 'the retelling of certain geographies that are taken for granted because they emanate from authoritative sources' (Cieri 2003a, 149), a concern that has been central to feminist methodologies, post-structuralist theory and critical social geography. For Mattingly (2001), in her account of using theatre as a powerful means for young people to represent their concerns, this type of representation occurred in two ways. First, through 'narrative authority', which gives traditionally powerless groups the power to shape the way their identities are represented, and secondly, through the ability of community theatre to represent the 'symbolic economy' of a neighbourhood, in this case a symbolic economy of multiculturalism.

Despite some concerns having been raised over the reality of participatory practice versus its sometimes glossy (or glossed over) presentation (Cooke and Kothari 2001; Mohan 1999; Pain and Francis 2003), major questions remain over the interplays between academic researchers, other participants and the vehicles and outlets in which 
findings are presented. At the analysis stage, some address this by asking participants to undertake data analysis or verification; others attempt to represent exactly what all participants said; some use mainstream modes of qualitative analysis arguing that transparency of procedures is important (Pain and Francis 2004). Our position eventually necessitates having to, as Leyshon (2002) puts it, transfer 'meaning from one context - the field - to another - the academic'; geographers doing PR ultimately represent others one way or another (Cieri 2004). For Cameron and Gibson (forthcoming), a poststructuralist approach to PR insists on multiple local representations and knowledges, which must be 'approached with a degree of caution...not blindly accepted at face value as inherently transformative' (8).

We also theorise, which has received little attention in accounts of geographers' activism (Dempsey and Rowe 2004), yet theories and understandings are unlikely to be shared by those with different cultural backgrounds (Randstrom and Deur 1999). Staeheli (2004) recounts her dilemma in taking a theoretical approach which involves dismantling dualisms which her research population used specifically for political effect. Often, too, the topics and categories which PR begins with arise from academic or policy perspectives, and so claims of 'bottom up' research are limited. Social geographers have been more successful in collaborative writing, some jointly attributing academic publications (e.g. Pratt 1999; Townsend et al 1995, Cahill et al forthcoming), and many others co-authoring reports, press releases, websites and other materials (see Cahill's www.fed-up-honeys.org for an example).

\section{Centre or margins? The squeezing of $P R$}

So PR has much to offer current debates about doing social geography. At the same time, growing institutional pressures affect geographers' ability to undertake action research approaches such as PR (Pain and Bailey forthcoming), as

'The desire to maintain the power of the academy in knowledge production and the desire to shape the education system for the purposes of the status quo... pressure academics to produce certain kinds of knowledge and to undertake particular types of praxis' Fuller and Kitchin $(2004,10)$.

Obtaining funding for PR is not straightforward, where participants are to be involved in setting research aims and contributions to 'the cutting edge' can not necessarily be predicted. Neither is effecting change, one of the main motivations behind PR, guaranteed (Blackburn and Holland 1997; Pain and Francis 2003). Dedicating time to the many activities involved in PR is difficult. Researchers may be partially integrated into outside communities - though these relationships can become fraught with difficulty (Monk et al 2003) - but feel isolated from other geographers. While PR is taking place across a wide scope of social geography, it is not highly visible, reflecting the elitist division between theory and action in geography as well as the assumption that PR only involves the second. That the practice of PR is gendered is at the heart of this; women and feminist geographers predominate. PR is simultaneously more public outside geography, and more private within it, than other forms of activism, blurring personal and professional lines and lives, and often involving reciprocal/caring roles (see Pratt 1998). In highlighting this issue I am wary of essentialising either women researchers in geography, most of whom do not use PR, or PR itself, which can be done in different ways. 


\section{Conclusion}

Most of the research projects included in this review resulted in action and change by and for research participants. Some social geographers also encourage students to experience participatory research (see Cope and Halfhill 2003; www.geog.psu.edu/phila/description.html; Public Interest Research Groups in Canada www.pirg.ca); provide training for non-academics (http://northumbria.ac.uk/peanut); and engage in parallel debates over participatory approaches in policy and planning spheres (e.g. O'Reilly 2003; Perrons 2004; Townsend et al 2002). Despite strong critiques, and ultimately irresolvable debates over whether a non-hierarchical academic/subject relationship is possible, there are clear benefits to social geographers doing PR, using legitimacy gained from academic status and ability to engage in 'scientific discourse' to actively work against inequality (Fuller 1999; Wilton 2004). PR often represents a vast improvement on conventional modes of research, but occasionally theory and practice have a tone of moralism and 'near religious fervour' (Mohan 1999, 44), of knowing what is best for participants, a surety that the academic's political and theoretical slant on their problems is the right one and a failure to engage in self critique. This underlines the continuing importance of self-reflexivity and critique, demonstrated in much of the important and effective research of feminist and social geographers referenced here. 


\section{Footnotes}

1 The term 'academic researcher' is used to distinguish geographers' involvement in this process from that of other participants. 


\section{References}

Abbott, J. et al. 1998: Participatory GIS: opportunity or oxymoron? PLA Notes 33, 27-34.

Bailey, C., Convery, I., Mort, M. and Baxter, J. 2004: Different public health geographies of the 2001 foot and mouth disease epidemic: 'citizen' versus 'professional' epidemiology. Unpublished paper available from authors.

Blake, M. 2004: personal communication: research on home, work and community for women in the UK and Hungary, Sheffield University.

Breitbart, M. 2003: Participatory research. In Clifford, N. and Valentine, G., editors, Key Methods in Geography London: Sage.

Cahill, C. forthcoming 2004: Defying gravity? Raising consciousness through collective research. Children's Geographies.

Cahill, C., Arenas, E., Contreras, J., Jiang, N., Rios-Moore, I. and Threatts, T. forthcoming 2004: Speaking back: voices of young urban womyn of color. In Harris, A., editor, All About the Girl: Power, Culture and Identity New York: Routledge.

Cameron, J. and Gibson, K. forthcoming: Participatory action research in a poststructuralist vein. Geoforum

Chambers, R. 1997: Whose Reality Counts; Putting the Last First. London: Intermediate Technology Publications.

Chouinard, V. 2000: Getting ethical: for inclusive and engaged geographies of disability. Ethics, Place and Environment 3, 70-80.

Chouinard, V. 2004: personal communication, McMaster University.

Cieri, M. 2003a: Between being and looking: queer tourism promotion and lesbian social space in Greater Philadelphia. ACME 2, 2, 147-66.

Cieri, M. 2003b: Drawing on perception: re-territorializing space and place from African-American perspectives. Paper presented at the AAG, New Orleans.

Cieri, M. 2004: Irresolvable geographies. Unpublished paper available from author.

Cloke, P. 2002: Deliver us from evil? Prospects for living ethically and acting politically in human geography. Progress in Human Geography 26, 5, 587-604.

Cooke, B. and Kothari, U., editors., 2001: Participation: the new tyranny? London: Zed Books.

Cope, M. and Halfhill, J. 2003: Progress Report: Buffalo Kids' Space Project. State University of New York at Buffalo. Available from author. 
Cravey, A. J., Arcury, T. A. and Quandt, S. A. 2000: Mapping as a means of farmworker education and empowerment. Journal of Geography 99, 229-37.

Dempsey, J. and Rowe, J. K. 2004: Why poststructuralism is a live wire for the left. In Fuller, D. and Kitchin, R., editors: Radical theory, critical praxis: making a difference beyond the academy? ACME e-book series, 32-51.

Dolan, C., Opondo, M. and Smith, S. 2003: Gender rights and participation in the Kenya cut flower industry. Natural Resources Institute Report no. 2768. SSR Project no. R8077 2002-4, Natural Resources Institute, Kent, UK.

Elwood, S. 2004: GIS, spatial stories, and negotiating multiple visions of neighbourhood revitalization. Paper presented to the AAG, Philadelphia.

Freeman, E. 2004: personal communication, McMaster University.

Freire, P. 1972: Pedagogy of the Oppressed. Harmondsworth: Penguin.

Fuller, D. 1999: Part of the action, or 'going native'? Learning to cope with the 'politics of integration'. Area 31, 3, 221-9.

Fuller, D., Mellor, M., Affleck, A. and Dodds, L. 2003: Advancing Financial Inclusion in Newcastle upon Tyne. Newcastle upon Tyne: University of Northumbria.

Fuller, D., O'Brien, K. and Hope, R. 2003: Exploring Solutions to 'Graffiti' in Newcastle upon Tyne. Newcastle upon Tyne: University of Northumbria.

Fuller, D. and Kitchin, R. 2004: Radical theory/critical praxis: academic geography beyond the academy? In Fuller, D. and Kitchin, R., editors: Radical theory, critical praxis: making a difference beyond the academy? ACME e-book series, 1-20.

Gaskell, C. 2002: Active Youth Citizenship: a Response to Street Crime and Violence. Queen Mary University of London. Available from author.

Gill, S. and Pain, R. 2002: Nothing To Do and Nowhere To Go! Report to Durham City Centre Youth Project. Durham: University of Durham.

Gregson, N. 2003: Reclaiming 'the social' in social and cultural geography. In Anderson, K., Domosh, M., Pile, S. and Thrift, N., editors, Handbook of Cultural Geography London: Sage, 43-57.

Guijt, I. and Shah, M., editors, 1998: The myth of community: gender issues in participatory development London: Intermediate Technology Publications.

Hartfield, M. and Kindon, S. 2003: Participatory heritage assessment: an example from Wellington, Aotearoa/ New Zealand. PLA Notes 46, 67-72.

Henkel and Stirrat 2001: in Cooke, B. and Kothari, U. editors., 2001: Participation: the new tyranny? Zed Books, London 
Herlihy, P. and Knapp, G. 2003: Maps of, by, and for the people of Latin America. Human Organization 62, 4, 303-14.

Herman, T. and Mattingly, D. J. 1999: Community, justice, and the ethics of research: negotiating reciprocal research relations. In Proctor, J. D. and Smith, D. M., editors, Geography and Ethics: Journeys in a Moral Terrain London: Routledge, 20922.

Juckes Maxey, L. 2004: The participation of younger people within intentional communities: evidence from two case studies. Children's Geographies 2, 1, 29-48.

Kesby, M. 2000: Participatory diagramming: deploying qualitative methods through an action research epistemology. Area 32, 4, 423-35.

Kesby, M. 2003: Participatory diagramming and the ethical and practical challenges of helping Africans themselves to 'map the issues' around HIV. In Kalipeni, E., Craddock, S., Oppong, J., Ghosh, J., editors, HIV and AIDS in Africa: Beyond Epidemiology. Oxford: Blackwell.

Kesby, M. 2004: Re-theorising empowerment-through-participation as a performance in space: beyond tyranny to transformation. Available from author.

Kesby, M., Kindon, S. and Pain, R. 2004: Participatory research. In Flowerdew, R. and Martin, M., editors, Methods in Human Geography London: Pearson.

Kindon, S. L. 1995: Dynamics of difference: exploring empowerment methodologies with women and men in Bali. New Zealand Geographer 51, 11, 1012.

Kindon, S. 1998: Of mothers and men: questioning gender and community myth in Bali. In Guijt, I. and Shar, M. K., editors, The Myth of Community: Gender Issues in Participatory Development. London: Intermediate Technology Publications, 152-168.

Kindon, S. 2003: Participatory video in geographic research: a feminist practice of looking? Area 35, 2.

Kindon, S. and Latham, A. 2002: From mitigation to negotiation: ethics and the geographical imagination in Aotearoa/New Zealand. New Zealand Geographer 58, 1, $14-22$.

Kitchin, R. 1999: Morals and ethics in geographical studies of disability. In Proctor, J. D. and Smith, D. M., editors, Geography and Ethics: Journeys in a Moral Terrain London: Routledge, 223-36

Kitchin, R. 2001: Using participatory action research approaches in geographical studies of disability: some reflections. Disability Studies Quarterly 21, 4, 61-69.

Kitchin, R. M. and Hubbard, P. J. 1999: Editorial: research, action and 'critical' geographies. Area 31, 3, 195-8. 
Kobayashi, A. 2003: GPC ten years on: is self-reflexivity enough? Gender Place and Culture 10, 4, 345-49.

Kwan, M. P. 2002: Is GIS for women? Reflections on the critical discourse in the 1990s. Gender Place and Culture 9, 3, 271-9.

Leavitt, J., Lingafelter, T. and Morello, C. 1998: Through their eyes: young girls look at their Los Angeles neighbourhood. In Ainley, R., editor, New Frontiers of Space, Bodies and Gender. London: Routledge, 76-87.

Lennie, J. 1999: Deconstructing gendered power relations in participatory planning: towards an empowering feminist framework of participation and action. Womens Studies International Forum 22, 1, 97-112.

Lewin, K. 1946: Action research and minority problems. Journal of Social Issues 2, 4, 34-46.

Leyshon, M. 2002: On being 'in the field': practice, progress and problems in research with young people in rural areas. Journal of Rural Studies 18, 179-91.

Maguire, P. 1987: Doing participatory research: a feminist approach. Amherst, Massachusetts: Centre for International Education, University of Massachusetts.

Matthews, H. and Limb, M. 1999: Defining an agenda for the geography of children: review and prospect. Progress in Human Geography 13, 1, 61-90.

Mattingly, D. 2001: Place, teenagers and representations: lessons from a community theatre project. Social and Cultural Geography 2, 4, 445-59.

McEwan, C. 2003: Material geographies and postcolonialism. Singapore Journal of Tropical Geography, 24, 3.

McFarlane, H. 2004: personal communication, University of Edinburgh.

McIntyre, A. 2000: Inner-City Kids: Adolescents Confront Life and Violence in an Urban Community. New York: New York University Press.

McIntyre, A. 2003: Through the eyes of women: photovoice and participatory research as tools for reimagining place. Gender Place and Culture 10, 1, 47-66.

Mohan, G. 1999: Not so distant, not so strange: the personal and the political in participatory research. Ethics Place and Environment 2, 1, 41-54.

Momsen, J. H. 2003: Participatory development and indigenous communities in the Mexican Caribbean, in Pugh, J. and Potter, R. B., editors, Participatory Planning in the Caribbean: Lessons from Practice. Aldershot: Ashgate, 155-72. 
Monk, J., Manning, P. and Denman, C. 2003: Working together: feminist perspectives on collaborative research and action. ACME: An International E-Journal for Critical Human Geographies 2, 1, 91-106.

Moser, C. and McIlwaine, C. 1999: Participatory urban appraisal and its application for research on violence. Environment and Urbanization 11, 2, 203-26.

Moser, C. and McIlwaine, C. 2000: Urban Poor Perceptions of Violence and Exclusion in Colombia. Washington DC: World Bank.

Moser, C. and McIlwaine, C. order of surnames? 2001: Violence and social capital in urban poor communities: perspectives from Colombia and Guatemala. Journal of International Development 13, 965-84.

Nairn, K., Panelli, R. and McCormack, J. 2003: Destablizing dualisms: young people's experiences of rural and urban environments. Childhood 10, 1, 9-42.

Nairn, K. and Smith, A. 2003: Young people as researchers in schools: the possibilities of peer research. Paper presented at American Educational Research Association Conference, Chicago, 21-25 April 2003.

Offen, K. 2003: Narrating place and identity, or mapping Miskitu land claims in Northeastern Nicaragua. Human Organization 62, 4, 382-92.

Opondo, M. 2003: The gender implications of tobacco contract farming in Kenya. Report to the Rockefeller Foundation, Nairobi, Kenya.

O'Reilly, K. 2003: Competing logics of women's participation in a Rajasthan Development Project. In Singh S (ed) Institutions, Traditions and People Jaipur: Rawat.

Pain, R. 2003a: Social geography: on action-orientated research. Progress in Human Geography 27, 5, 677-85.

Pain, R. 2003b: Youth, age and the representation of fear. Capital and Class 60, 15171.

Pain, R. and Bailey, C. (forthcoming) Country review: British social and cultural geography. Social and Cultural Geography

Pain, R. and Francis, P. 2003: Reflections on participatory research. Area 35, 1, 4654.

Pain, R. and Francis, P. 2004: Living with crime: spaces of risk for homeless young people. Children's Geographies 2, 1, 95-110.

Peake, L. (on behalf of Red Thread Women's Development Programme) 2000: Women Researching Women: Methodology Report and Research Projects on the Study of Domestic Violence and Women's Reproductive Health in Guyana. Georgetown, Guyana: Inter-American Development Bank. 
Perrons, D. 2004: Globalization, participation and empowerment. In Perrons, D. Globalization and Social Change: People and Places in a Divided World. London: Routledge.

Pratt, G. in collaboration with the Philippine Women Centre 1999: Is this Canada? Domestic workers' experiences in Vancouver, BC. In Momsen, J. H., editor, Gender, Migration and Domestic Service. London: Routledge, 23-42.

Pratt G (1998) Comments on activism, in Lost and found in the posts: addressing critical human geography. Environment and Planning D: Society and Space 16, 3, 264-5.

Pratt, G. 2000: Participatory action research. In Johnston, R., Gregory. D, Pratt, G. and Watts, M., editors, Dictionary of Human Geography Fourth Edition. Oxford: Blackwell, 574.

Pratt, G. and Kirby, E. 2003: Performing nursing: the BC Nurses Union Theatre Project. ACME: An International E-Journal for Critical Human Geographies 2, 1, 1432.

Proctor, J. D. and Smith, D. M., editors, Geography and Ethics: Journeys in a Moral Terrain London: Routledge

Pugh, J. and Potter, R. B., editors, Participatory Planning in the Caribbean: Lessons from Practice. Aldershot: Ashgate

Rambaldi, G. and Lanh, L. V. 2003: The seventh helper: the vertical dimension feedback from a training exercise in Vietnam. PLA Notes 46, 77-83.

Randstrom, R. and Deur, D. 1999: Reciprocal appropriation: towards an ethics of cross-cultural research. In Proctor, J. D. and Smith, D. M., editors, Geography and Ethics: Journeys in a Moral Terrain London: Routledge, 237-50.

Rocheleau, D. E. and Thomas-Slayter, B. 1995: Gender, Environment and Development in Kenya: A Grassroots Perspective. Boulder: L. Rienner.

Sanderson, E. and Kindon, S. 2004: Progress in participatory development: opening up the possibility of knowledge through progressive participation Progress in Development Studies 4, 2, 114-26.

Smith, D. A. 2003: Participatory mapping of community lands and hunting yields among the Bugle of Western Panama. Human Organization 62, 4, 332-43.

Smith, F. 2004: Is there a place for children's geographers in the policy arena? Children's Geographies 2, 1, 157-61.

Staeheli, L. 2004 It is critical to be political, but how do we do it? Working paper, Institute of Behavioral Science, Colorado University 
Stocks, R. 2003: Mapping dreams in Nicaragua's Bosawas Reserve. Human Organization 62, 4, 344-56.

Townsend, J. with Arrevillaga, U. et al., 1995: Women's Voices from the Rainforest. London, Routledge.

Townsend, J. G., Porter, G. and Mawdsley, E. E. 2002: The role of the transnational community of non-governmental organisations: governance or poverty reduction? Journal of International Development 14, 6, 829-39.

Whyte, W. F. 1991: Participatory Action Research. London, Sage.

Williams, C. and Dunn. C, 2003: GIS in participatory research: assessing the impact of landmines on communities in north-west Cambodia. Transactions in GIS 7, 393410.

Wilton, R. 2004: Keeping your distance? Balancing political engagement and scientific autonomy with a psychiatric consumer/survivor group. In Fuller, D. and Kitchin, R., editors: Radical theory, critical praxis: making a difference beyond the academy? ACME e-book series, 116-31.

Young, L. and Barratt, H. 2001: Adapting visual methods: action research with Kampala street children. Area 33, 2, 141-52,

Young, T. 2003: 'It's strange kids coming in': young people and belonging in a community undergoing residential restructuring. Paper presented at the AAG, New Orleans. 